\title{
Contralateral Approach to Coil Embolization of Proximal A1 Aneurysms Using the Anterior Communicating Artery
}

\author{
(D)H.J. Kwon, (D)Y.D. Cho, (D).W. Lim, DH.-S. Koh, DD.H. Yoo, DH.-S. Kang, and (D) M.H. Han
}

\begin{abstract}
BACKGROUND AND PURPOSE: Aneurysms arising from the proximal A1 segment of the anterior cerebral artery are rare, and their distinctive configurations often pose technical challenges during endovascular embolization. Herein, we present 11 patients with proximal $\mathrm{Al}$ aneurysms requiring a contralateral approach (via the anterior communicating artery) to coil embolization.
\end{abstract}

MATERIALS AND METHODS: From a prospectively collected data repository, we retrieved records of 11 patients consecutively treated for proximal Al aneurysms between January 2011 and March 2018. In each instance, coil embolization was performed by the contralateral route. Outcomes were analyzed in terms of morphologic features and clinical status.

RESULTS: Aneurysms in all 11 patients were directed posteriorly and were small $(<5 \mathrm{~mm})$. A contralateral approach (via the anterior communicating artery) was used after ipsilateral attempts at aneurysm selection failed in each instance, despite using a variety of microcatheters. Single punctures and single guiding catheters sufficed in 9 patients, but 2 patients required dual punctures and 2 guiding catheters. All endovascular treatments ultimately yielded excellent outcomes. Although 1 symptomatic infarct was manifested in the course of ipsilateral treatment, no morbidity or mortality resulted from the contralateral access.

CONCLUSIONS: Due to angio-anatomic constraints, a contralateral strategy for coil embolization of proximal A1 aneurysms is acceptable if ipsilateral access is technically prohibitive and the vessels (contralateral Al and anterior communicating artery) are amenable to the passage of microdevices.

ABBREVIATION: AcomA $=$ anterior communicating artery

$\mathbf{P}$ recommunicating (A1) segment aneurysms of the anterior cerebral artery are rare and pose technical challenges for both surgical clipping and endovascular coiling. According to relevant reports, on open surgical access, an important issue in treating proximal Al aneurysms is branch or perforator injury during dissection or clipping. ${ }^{1}$ Endovascular embolization of proximal A1 aneurysms is also technically problematic, given the distinctive features of such lesions (ie, diminutive size, proximity to the internal carotid artery bifurcation, and association with perforators). ${ }^{2-5}$ Aneurysm selection by microcatheter is perhaps most

Received June 26, 2018; accepted after revision September 28

From the Department of Neurosurgery (H.-J.K., J.W.L., H.-S. Koh), Regional Cerebrovascular Center, Chungnam National University Hospital, Chungnam National University College of Medicine, Daejeon, Korea; and Departments of Radiology (Y.D.C., D.H.Y., M.H.H.) and Neurosurgery (H.-S. Kang), Seoul National University Hospital, Seoul National University College of Medicine, Seoul, Korea.

Please address correspondence to Young Dae Cho, MD, PhD, Department of Radiology, Seoul National University College of Medicine, 101 Daehak-Ro, Jongno-Gu,

Seoul, 03080, Korea; e-mail: aronnn@naver.com

三 Indicates article with supplemental on-line table.

http://dx.doi.org/10.3174/ajnr.A5875 difficult in this setting, particularly in proximal segment lesions directed posteriorly. If an ipsilateral approach failed in selecting proximal Al aneurysms, despite the use of several microcatheters and exhaustive effort, we applied a contralateral approach (via the anterior communicating artery [AcomA]) to consecutively select these problematic lesions. The feasibility and safety of this approach were thus explored in a limited group of patients whose angiographic and clinical outcomes are detailed herein.

\section{MATERIALS AND METHODS Patient Population}

A total of 4172 patients with 5391 aneurysms, including 1215 lesions impinging on the anterior cerebral artery, underwent coil embolization at 2 institutions between January 2011 and March 2018. Proximal A1 aneurysms accounted for 70 of these lesions, 59 of which were successfully treated by an ipsilateral approach. The remaining 11 aneurysms either could not be selected by microcatheters, or coil insertion failed due to unfavorable orientation or poor microcatheter support. Clinical and radiographic features of aneurysms in the patients under study (women, 8; men, 3 ; mean age, $53.2 \pm 12.0$ years), culminating in selection by 
Summary of patient data

\begin{tabular}{lcccccclll}
\hline No. & Age $(\mathbf{y r})$ & Sex & $\begin{array}{c}\text { An } \\
\text { Status }\end{array}$ & $\begin{array}{c}\text { Size of } \\
\text { An }(\mathbf{m m})\end{array}$ & $\begin{array}{c}\text { D/N } \\
\text { Ratio }\end{array}$ & $\begin{array}{c}\text { Double } \\
\text { Guiding/Puncture }\end{array}$ & $\begin{array}{c}\text { Degree of } \\
\text { Occlusion }\end{array}$ & Complication & Follow-Up \\
\hline 1 & 61 & M & UR & 2.8 & 0.8 & Single & Near-total & None & Complete occlusion at 18 mo \\
2 & 61 & F & UR & 3.4 & 1.4 & Single & Subtotal & Symptomatic infarction & Minor recanalization at 18 mo \\
3 & 36 & F & UR & 2.4 & 1.4 & Single & Near-total & None & Complete occlusion at 18 mo \\
4 & 41 & M & UR & 3.1 & 2.1 & Single & Total & None & Complete occlusion at 72 mo \\
5 & 60 & M & UR & 2.6 & 2.0 & Single & Total & None & Complete occlusion at 48 mo \\
6 & 62 & F & UR & 3.8 & 2.3 & Single & Near-total & None & Complete occlusion at 6 mo \\
7 & 39 & F & UR & 3.0 & 1.9 & Single & Near-total & None & No follow-up \\
8 & 52 & F & UR & 2.7 & 1.2 & Double & Total & None & Complete occlusion at 18 mo \\
9 & 42 & F & UR & 2.6 & 1.5 & Double & Total & None & Complete occlusion at 6 mo \\
10 & 58 & F & UR & 3.0 & 2.0 & Single & Total & None & Complete occlusion at 6 mo \\
11 & 73 & F & UR & 3.5 & 1.8 & Single & Near-total & None & No follow-up \\
\hline
\end{tabular}

Note:-An indicates aneurysm; D/N, depth to neck; UR, unruptured.
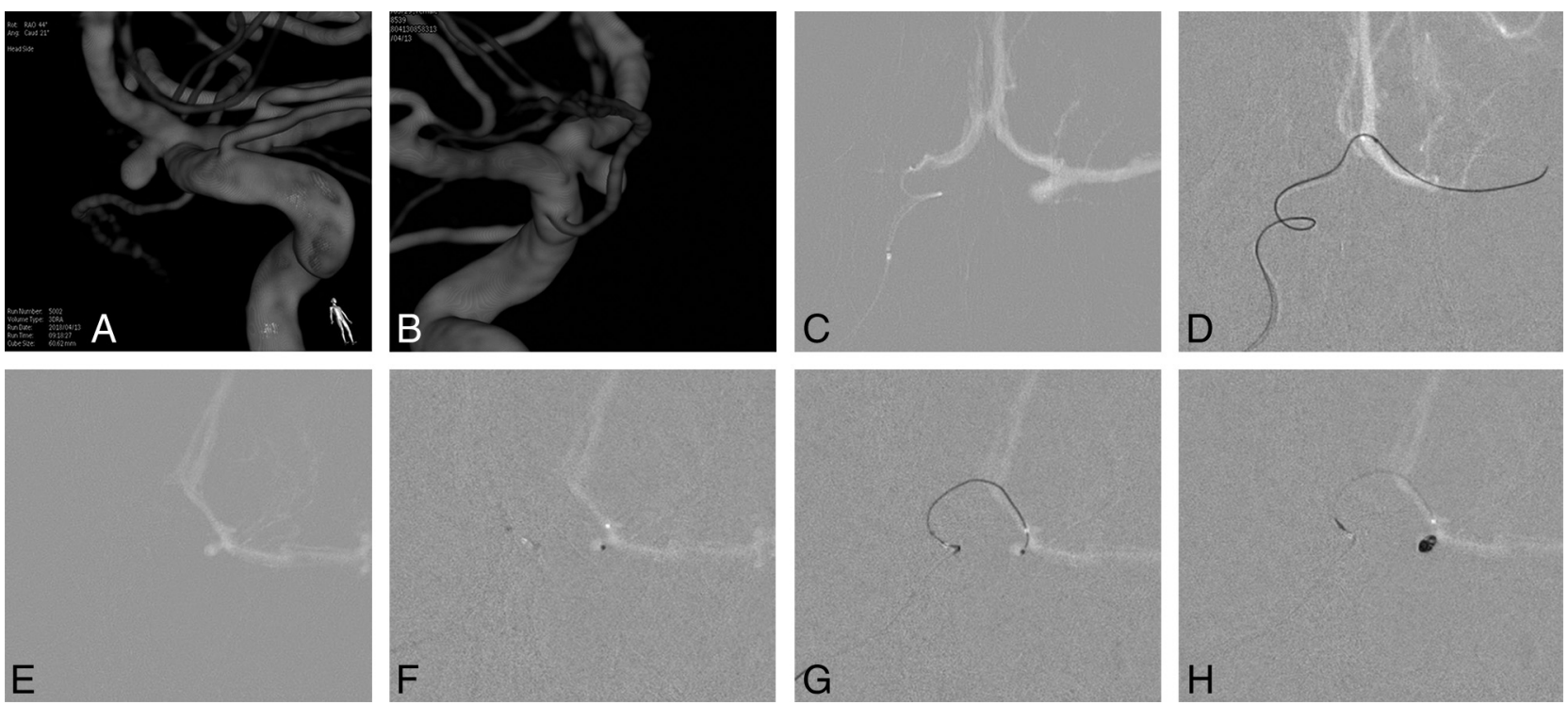

FIG 1. $A$ and $B, 3 D$ image demonstrates a left proximal $A 1$ aneurysm. $C$, Microcatheter navigated from the contralateral $A 1$ into the anterior communicating artery. $D$, Retrograde introduction of a microcatheter into the ipsilateral $A 1$ via the AcomA. $E$, Use of a microcatheter for selective angiography, delineating the configuration of the aneurysm. $F$, Saccular insertion of a microcatheter. $G$ and $H$, Coil embolization undertaken using a single catheter.

a contralateral approach, are shown in the Table. All aneurysms were unruptured and small (largest diameter, $<5 \mathrm{~mm}$ ). After thorough evaluation, perceived risks, benefits, and treatment options (including aneurysm clipping) were discussed with each patient and family, who then granted informed consent. Therapeutic alternatives were formulated by neurosurgical and neurointerventional teams in a multidisciplinary decision-making process. This study was conducted with approval of institutional review boards at both hospitals.

\section{Therapeutic Strategy}

As depicted in Fig 1, we took the following tactical steps: 1) microcatheter delivery into the contralateral ICA; 2) retrograde advancement of the microcatheter into the ipsilateral distal A1 segment through the patent AcomA; 3) selective angiography of the proximal A1, close to the aneurysm; 4) selection of the aneurysm by the microcatheter; 5) framing the aneurysm with the first coil, sufficiently lengthy for coil stability; and 6) filling the residual sac with coils.

This technique is not advocated as a first-line method and is unwarranted if ipsilateral coiling is achievable. Contralateral ac- cess (via the AcomA) was our recourse for aneurysm selection if repeat attempts at ipsilateral microcatheter delivery failed and key vessels (contralateral Al and AcomA) allowed passage of needed microdevices. Double guiding catheters generally may be used with the ipsilateral catheter serving for angiography and the contralateral catheter for coil delivery. In most of our series, however, use of a single guiding catheter and single femoral puncture readily sufficed in this setting because selective angiography performed before coiling, using the same microcatheter to then deliver the coil, furnished valuable angio-anatomic insight (Fig 1).

\section{Endovascular Procedure}

All the procedures were performed with the patient under general anesthesia. Configurations and arterial architectures of aneurysms were evaluated using Integris V and Allura Clarity (Philips Healthcare, Best, the Netherlands) or an Innova IGS 630 (GE Healthcare, Milwaukee, Wisconsin) biplane system, including 3D rotational angiography. In each patient, a 300-mg loading dose of clopidogrel was given 1 day in advance of the procedure, and it was supplemented by a morning dose $(75 \mathrm{mg})$ on the day of the procedure. Poor responders to clopidogrel (ie, P2Y12 reactivity 

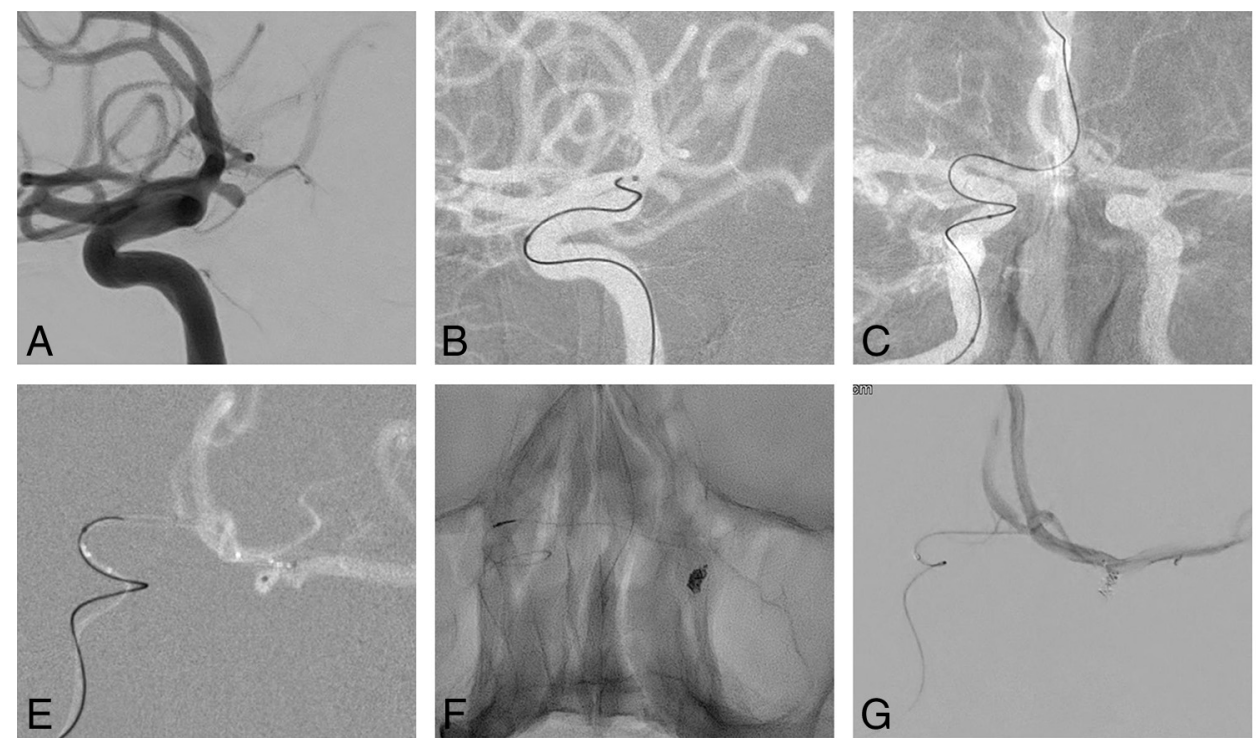

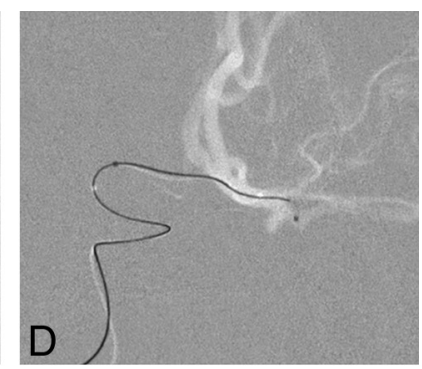

FIG 2. $A$, Conventional angiography shows a small proximal $\mathrm{Al}$ aneurysm directed posteriorly. $B$, Failure of aneurysm selection through the ipsilateral ICA, despite repeat attempts using variably shaped microcatheters. $C$ and $D$, Microcatheter for coil delivery navigated from the contralateral Al to the ipsilateral Al segment via the AcomA. E, The microcatheter is advanced into the sac after being used in selective angiography (near to the aneurysm). $F$, Coil insertion performed. $G$ and $H$, Completion angiography confirms total occlusion of the aneurysm.

units of $>285$, indicated by the VerifyNow P2Y12 assay [Accumetrics, San Diego, California]) received aspirin as well (300-mg loading dose). A bolus of heparin (3000 IU) was administered after femoral artery sheath placement, intermittent bolus doses ( $1000 \mathrm{IU} / \mathrm{h}$ ) were delivered thereafter, and activated clotting times were monitored. Following procedures, no maintenance antiplatelet medications were routinely prescribed.

\section{Immediate and Final Outcome}

Degrees of saccular occlusion were gauged during completion angiography using a 3-point scale of contrast retention: total occlusion (no residual filling), near-total occlusion (minimal residual filling at the base), and subtotal occlusion (any saccular filling). Clinical outcomes were assessed using the Glasgow Outcome Score, and follow-up anatomic results were categorized as complete occlusion, minor recanalization, or major recanalization.

\section{RESULTS}

In all 11 instances, the aneurysms were directed posteriorly and were devoid of branches. The maximum diameter of each was $<5$ $\mathrm{mm}$. Angio-anatomic configurations related to the aneurysms, including the ipsilateral A1, contralateral A1, AcomA diameter, and so forth, are summarized in the On-line Table. The ipsilateral approach had regularly failed in microcatheter selection of proximal A1 aneurysms, despite multiple attempts using variably shaped catheters, so a contralateral approach via the AcomA was used. Single punctures and single guiding catheters sufficed for coil embolization in 9 patients, but 2 patients required dual punctures and 2 guiding catheters. A distal access catheter was used in 1 older patient. Immediately after coil embolization, 10 aneurysms appeared successfully occluded with a residual sac persisting in only 1 lesion. A procedure-related adverse event occurred in 1 patient who had symptomatic infarction. The ischemia was induced in the course of selecting the aneurysm by an ipsilateral (not a contralateral) approach. Nine patients (2 treated recently being exempt) underwent follow-up evaluations, including MRA and/or conventional angiography. Eight patients showed complete occlusion, without recanalization. In 1 patient, minor recanalization was evident. There were no delayed complications such as thromboembolic infarction or hemorrhage.

\section{Patient 6}

A 62-year-old woman was admitted for treatment of an unruptured, posteriorly directed left proximal A1 aneurysm $(3.8 \mathrm{~mm}$; depth-to-neck ratio, 2.3). The A1 segment (diameter, $2.2 \mathrm{~mm}$ ) of the anterior cerebral artery originated from the ICA at an acute angle $\left(58^{\circ}\right)$, but the contralateral A1 $(1.5 \mathrm{~mm})$ and AcomA (1.6 $\mathrm{mm}$ ) were of sufficient caliber to allow microcatheter passage. Once a $6 \mathrm{~F}$ guiding catheter was placed in the cervical portion of left ICA, aneurysm selection by microcatheter was attempted repeatedly but failed, despite various catheter shapes (including steam-shaped $\mathrm{S}$ and preshaped S) used. The guiding catheter was then moved into the right ICA, and a preshaped $\mathrm{C}$ microcatheter was navigated retrograde from the right $\mathrm{A} 1$ into the left $\mathrm{A} 1$ via the AcomA. The microcatheter was first used for selective angiography of the proximal A1 close to the aneurysm, delineating its configuration. Once introduced into the sac, a frame coil of adequate length for stability was inserted, and additional coiling was performed. The aneurysm was thereby successfully occluded, and the patient was discharged complication-free on the following day (Fig 2).

\section{DISCUSSION}

A retrograde or nonantegrade approach to coil embolization was first described by Moret et al, in $2000 .{ }^{6}$ In their series, aneurysms subjected to this innovative technique were situated as follows: basilar bifurcation, 5; ICA bifurcation, 2; posterior communicating artery, 2; superior cerebellar artery, 2; and posterior inferior cerebellar artery, 1 . The balloon-remodeling technique was used in all lesions. With the same objective in mind, a number of au- 
thors have described the use of a retrograde approach with stent assistance. ${ }^{7-12}$ Although their original intent was delivery of protection devices for optimal neck coverage, we believe that retrograde access is also useful in proximal Al aneurysms, helping in the selection of aneurysms after failed ipsilateral attempts. By comparison, a contralateral (versus ipsilateral) approach affords smoother routes to the aneurysm sacs. Although all aneurysms in this series were unruptured and devoid of branches, this retrograde approach may be applied even in their counterparts (when perforators arise from the aneurysm or the patient presents with hemorrhage) if the aneurysm configuration is suitable for coil embolization and key vessels (contralateral A1 and AcomA) are amenable to the passage of microdevices.

Selection of proximal A1 aneurysms is particularly difficult due to their small size, proximity to ICA bifurcation, and posterior orientation; and, the acutely angled origin of the A1 from the ICA bifurcation is problematic. As noted by Cho et al, ${ }^{13}$ a preshaped S-curve microcatheter may be preferential in the first attempts at ipsilateral selection. This microcatheter has a reported success rate of $63 \%$. In addition to proximal angulation, it bears a tightly angled distal aspect that is almost impossible to replicate by steam-shaping. However, Lee et $\mathrm{al}^{14}$ have similarly claimed that a Z-shaped microcatheter, formed by steam-shaping, is an asset under these circumstances. Although contralateral access is also feasible, the AcomA must be patent and capable of accommodating a microcatheter.

Another important point is that a retrograde approach via the AcomA does not always require 2 guiding catheters and dual femoral punctures. In double-guiding scenarios, 1 catheter generally serves for coil delivery and the other allows angiographic delineation of lesions. The present series, however, confirms that the use of a single guiding catheter and single femoral puncture readily suffices in this setting. Protection devices or additional microcatheters were not otherwise required in the patients we treated. These aneurysms were devoid of branches and were small enough to characterize through selective angiography using the same microcatheter intended for subsequent coil insertion.

At present, we do not advocate contralateral access as a firstline approach for embolization of proximal A1 aneurysms. The efficacy and safety of this approach must be further established in a larger study population. Nevertheless, it may constitute a viable alternative in disadvantaged situations in which standard methods do not apply.

\section{CONCLUSIONS}

Given the inherent angio-anatomic hindrances to coil embolization of proximal A1 aneurysms, a contralateral approach may be reasonable if ipsilateral access proves prohibitive and key vessels (the contralateral A1 and AcomA) are amenable to the passage of microdevices.

Disclosures: Moon Hee Han—UNRELATED: Consultancy: Microvention. * *Money paid to the institution.

\section{REFERENCES}

1. Lee JM, Joo SP, Kim TS, et al. Surgical management of anterior cerebral artery aneurysms of the proximal (A1) segment. World Neurosurg 2010;74:478-82 CrossRef Medline

2. Suzuki M, Onuma T, Sakurai Y, et al. Aneurysms arising from the proximal (A1) segment of the anterior cerebral artery: a study of 38 cases. J Neurosurg 1992;76:455-58 CrossRef Medline

3. Wanibuchi M, Kurokawa Y, Ishiguro M, et al. Characteristics of aneurysms arising from the horizontal portion of the anterior cerebral artery. Surg Neurol 2001;55:148-54; discussion 154-55 CrossRef Medline

4. Dashti R, Hernesniemi J, Lehto H, et al. Microneurosurgical management of proximal anterior cerebral artery aneurysms. Surg Neurol 2007;68:366-77 CrossRef Medline

5. Wakabayashi T, Tamaki N, Yamashita H, et al. Angiographic classification of aneurysms of the horizontal segment of the anterior cerebral artery. Surg Neurol 1985;24:31-34 CrossRef Medline

6. Moret J, Ross IB, Weill A, et al. The retrograde approach: a consideration for the endovascular treatment of aneurysms. AJNR Am J Neuroradiol 2000;21:262-68 Medline

7. Blackburn SL, Kadkhodayan Y, Shekhtman E, et al. Treatment of basilar tip aneurysms with horizontal PCA to PCA stent-assisted coiling: case series. J Neurointerv Surg 2013;5:212-16 CrossRef Medline

8. Pride GL Jr, Welch B, Novakovic R, et al. Retrograde crossing stent placement strategies at the basilar apex for the treatment of wide necked aneurysms: reconstructive and deconstructive opportunities. J Neurointerv Surg 2009;1:132-35 CrossRef Medline

9. Puri AS, Erdem E. Unusual intracranial stent navigation through the circle of Willis in a patient with recurrent basilar tip aneurysm during stent-assisted coiling: a case report. Interv Neuroradiol 2009; 15:81-86 CrossRef Medline

10. Kelly ME, Turner R, Gonugunta V, et al. Stent reconstruction of wide-necked aneurysms across the circle of Willis. Neurosurgery 2007;61(5 Suppl 2):249-54 CrossRef Medline

11. Cho YD, Kim KM, Lee WJ, et al. Retrograde stenting through the posterior cerebral artery in coil embolization of the posterior communicating artery aneurysm. Neuroradiology 2013;55: 733-39 CrossRef Medline

12. Cho YD, Kang HS, Lee WJ, et al. Stent-assisted coil embolization of wide-necked posterior inferior cerebellar artery aneurysms. Neuroradiology 2013;55:877-82 CrossRef Medline

13. Cho YD, Ahn JH, Jung SC, et al. Coil embolization in precommunicating (A1) segment aneurysms of anterior cerebral artery. Neuroradiology 2014;56:219-25 CrossRef Medline

14. Lee HY, Ahn JS, Suh DC, et al. Z-shaped microcatheter tip shaping for embolization of aneurysms at the proximal A1 segment of the anterior cerebral artery: a technical note. Neurointervention 2011;6: 95-99 CrossRef Medline 